\title{
Elemental sulfur coarsening kinetics
}

\author{
Angel A Garcia Jr1,2 and Gregory K Druschel ${ }^{1,3^{*}}$
}

\begin{abstract}
Background: Elemental sulfur exists is a variety of forms in natural systems, from dissolved forms (noted as $S_{8(d i s s)}$ or in water as $S_{8(a q)}$ ) to bulk elemental sulfur (most stable as $a-S_{8}$ ). Elemental sulfur can form via several biotic and abiotic processes, many beginning with small sulfur oxide or polysulfidic sulfur molecules that coarsen into $S_{8}$ rings that then coalesce into larger forms:

$\mathrm{S}_{\mathrm{n}} \mathrm{O}_{\mathrm{m}}{ }^{2-} \rightarrow \mathrm{S}_{8(\mathrm{aq})} \rightarrow \mathrm{S}_{8(\mathrm{nano})} \rightarrow \mathrm{S}_{8(\mathrm{sol})} \rightarrow \mathrm{S}_{8(\alpha-\mathrm{S} 8)(\text { (bulk) }}$

Formation of elemental sulfur can be possible via two primary techniques to create an emulsion of liquid sulfur in water called sulfur sols that approximate some mechanisms of possible elemental sulfur formation in natural systems. These techniques produce hydrophobic $\left(S_{8(\text { Weimarn }}\right)$ and hydrophilic $\left(S_{8 \text { (polysulfide) }}\right)$ sols that exist as nanoparticle and colloidal suspensions. These sols begin as small sulfur oxide or polysulfidic sulfur molecules, or dissolved $\mathrm{S}_{8(\text { aq) }}$ forms, but quickly become nanoparticulate and coarsen into micron sized particles via a combination of classical nucleation, aggregation processes, and/or Ostwald ripening.

Results: We conducted a series of experiments to study the rate of elemental sulfur particle coarsening using dynamic light scattering (DLS) analysis under different physical and chemical conditions. Rates of nucleation and initial coarsening occur over seconds to minutes at rates too fast to measure by $D L S$, with subsequent coarsening of $S_{8(\text { nano) }}$ and $\mathrm{S}_{8(\mathrm{sol})}$ being strongly temperature dependent, with rates up to 20 times faster at $75^{\circ} \mathrm{C}$ compared to $20^{\circ} \mathrm{C}$. The addition of surfactants (utilizing ionic and nonionic surfactants as model compounds) results in a significant reduction of coarsening rates, in addition to known effects of these molecules on elemental sulfur solubility. DLS and cryo-SEM results suggest coarsening is largely a product of ripening processes rather than particle aggregation, especially at higher temperatures. Fitting of the coarsening rate data to established models for Ostwald ripening additionally support this as a primary mechanism of coarsening.

Conclusions: Elemental sulfur sols coarsen rapidly at elevated temperatures and experience significant effects on both solubility and particle coarsening kinetics due to interaction with surfactants. Growth of elemental sulfur nanoparticles and sols is largely governed by Ostwald ripening processes.
\end{abstract}

\section{Background}

Sulfur is a key element associated with interactions between magma chambers, primary and meteoric water, country rock, and the atmosphere in hydrothermal systems, in additional to being important as an electron donor or acceptor for a range of microbial metabolisms [1-4]. Sulfur exists on Earth between the most reduced

\footnotetext{
* Correspondence: gdrusche@iupui.edu

'Department of Geology, University of Vermont, Delehanty Hall, Burlington 05405, VT, USA

${ }^{3}$ Department of Earth Sciences, Indiana University-Purdue University Indianapolis, SL118, 723W. Michigan St., Indianapolis 46202, IN, USA Full list of author information is available at the end of the article
}

form, hydrogen sulfide $\left(\mathrm{S}^{2-}\right)$ and the most oxidized form, sulfate $\left(\mathrm{S}^{6+}\right)$. Sulfur polymerizes to form chains of sulfur molecules, and these chains can additionally cyclize to form rings [5,6]. Sulfur reacts with different organic molecules to form a large number of different organic-S compounds [7], though for simplicity we will consider only inorganic S chemistry here. Many of these forms of sulfur interact strongly with different metal ions, especially important is the interaction between sulfide and metals to form a number of insoluble metal sulfide minerals $[8,9]$. As electron transfers occur in one, or at most 2 , electron steps, there are a number of intermediate sulfur forms involved with redox reactions between

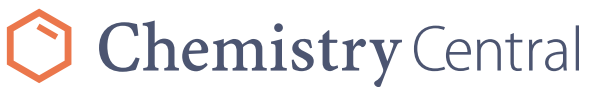


sulfide and sulfate [10]. Key dissolved intermediate sulfur compounds include polysulfides $\left(\mathrm{S}_{\mathrm{x}}{ }^{2-}\right.$, where $\mathrm{x}=2-9$ in most waters), thiosulfate $\left(\mathrm{S}_{2} \mathrm{O}_{3}{ }^{2-}\right)$, sulfane monosulfonic acids $\left(\mathrm{S}_{\mathrm{x}} \mathrm{O}_{3}{ }^{2-}\right.$, where $\mathrm{x}$ can be from 3 to over 100 but mostly in the 3-12 range in most waters), polythionates $\left(\mathrm{S}_{\mathrm{x}} \mathrm{O}_{6}{ }^{2-}\right.$, where $\mathrm{x}=3-6$ in most waters), and sulfite $\left(\mathrm{SO}_{3}{ }^{2-}\right)$. Several excellent reviews on detailed sulfur chemistry and geochemistry exist $[3,5,8,11,12]$.

Elemental sulfur is the ground state, or atomic, form of sulfur, $\mathrm{S}^{0}$, and is most stable in aqueous systems as the mineral elemental sulfur in the $\alpha-S_{8}$ configuration (space group Fddd) [5,13]. Sulfur in its atomic form $\left(S^{0}\right.$, here defined as a single $\mathrm{S}$ molecule with zero valence), should not be mistaken with mineral sulfur; $S^{0}$ has a high enthalpy of formation and is not stable at ambient temperature $[14,15]$. Sulfur atoms have a strong tendency to catenate, resulting in polymeric forms that can exist as rings or as chains of varying sizes and configurations, but is most stable as an 8-membered ring with a crown-shaped configuration $\left(\mathrm{S}_{8}\right)[5,13,14,16]$. Elemental sulfur in solid form exists as about 30 different allotropes that have been characterized; each varying in viscosity, color, and melting point [5,13]. These solid forms of elemental sulfur bring together these rings or chains with relatively weak van der Waals forces, this weak interaction makes elemental sulfur a soft mineral with a low melting point and high volatility [13]. $\alpha-S_{8}$ has a high refractive index (2.04) with high optical relief when transmitted light microscopy is used. The $\alpha-\mathrm{S}_{8 \text { (bulk) }}$ crystal has a large birefringence (0.29) that can be observed, even if they are only $0.5 \mu \mathrm{m}$ thick $[17,18]$.

Elemental sulfur is a product of a number of reactions, including the oxidation of hydrogen sulfide [19] and the acid dissociation of thiosulfate and polysulfides [20-22]. This product does not start as the $S^{0}$ atomic form, rather it is the result of a series of chain-lengthening reactions involving thiosulfate, sulfane monosulfonic acids, polythionates, polysulfides, and sulfite to generate at least a 9-sulfur chain that decomposes to $S_{8}$ [23], for example with thiosulfate via the reactions [23]:

$$
\begin{aligned}
& \mathrm{HS}_{2} \mathrm{O}_{3}{ }^{-}+\mathrm{S}_{2} \mathrm{O}_{3}{ }^{2-} \rightarrow \mathrm{S}_{3} \mathrm{O}_{3}{ }^{2-}+\mathrm{SO}_{3}{ }^{2-} \\
& \mathrm{HS}_{8} \mathrm{O}_{3}{ }^{-}+\mathrm{S}_{2} \mathrm{O}_{3}{ }^{2-} \rightarrow \mathrm{HS}_{9} \mathrm{O}_{3}{ }^{-}+\mathrm{SO}_{3}{ }^{2-} \\
& \mathrm{HS}_{9} \mathrm{O}_{3}{ }^{-} \rightarrow \mathrm{S}_{8} \text { (aq.) }
\end{aligned}
$$

The dissolved 8-sulfur ring-form of elemental sulfur $\left(\mathrm{S}_{8(\mathrm{aq})}\right)$, is sparingly soluble in water, but that solubility is strongly temperature dependent $-S_{8(a q)}$ concentrations in equilibrium with mineral sulfur $\left(\alpha-S_{8}\right)$ range from 6.1 $\mathrm{nM}$ at $4^{\circ} \mathrm{C}$ to $478 \mathrm{nM}$ at $80^{\circ} \mathrm{C}$ [24]. Solubility of $\mathrm{S}_{8(\mathrm{aq})}$ is also affected strongly by the presence of surfactants; the solubility of sulfur was found to increase 5000-fold in the presence of several model surfactants by Steudel and Holdt [25]. This was interpreted to be related to the formation of micelles of surfactant-type molecules with an $\mathrm{S}_{8}$ ring in the hydrophobic interior of these micelles.

The solubility of elemental sulfur is probably most significantly impacted by the equilibrium between elemental sulfur and hydrogen sulfide or bisulfide to form polysulfide, via the reaction [23,26-28]:

$$
(\mathrm{n}-1) / 8 \alpha-\mathrm{S}_{8 \text { (bulk) }}+\mathrm{HS}^{-} \rightarrow \mathrm{S}_{\mathrm{n}}{ }^{2-}+\mathrm{H}^{+}
$$

This reaction can constrain the solubility of elemental sulfur in many systems [29], where excess sulfide can quantitatively consume elemental sulfur [8]. The equilibrium constants for this reaction have been determined for temperatures up to $80^{\circ} \mathrm{C}[27,30]$, showing equilibrium polysulfide activities to be predominant at more alkaline $\mathrm{pH}$. The rate of forward reaction for this can be limited by surface area, as has been found to be the case for biologically produced sulfur [31]. The bioavailability of sulfur for microbial metabolisms may also be significantly affected by this reaction (4) with a role for $\mathrm{S}_{8(\mathrm{nano})}$ and polysulfides as a part of making different forms of sulfur more bioavailable $[4,32,33]$.

$\mathrm{S}_{8(\mathrm{aq})}$ rings will quickly aggregate to form very small, but visible, forms of sulfur [11,23,34]. These forms are often in the tens to hundreds of nanometers to few micron size range of particles, do not settle from solution, and display particle scattering effects when suspended in solution [11]. These colloidal suspensions of elemental sulfur compounds have been termed 'sols' and consist of a range of particles of varying surface character and composition that can be formed via abiotic and biotic processes (for a review of this, see [11]). Hydrophobic (Weimarn sols, $\mathrm{S}_{8 \text { (Weimarn) }}$ ) and hydrophilic (Raffo, $\mathrm{S}_{8 \text { (Raffo); }}$ LaMer, and Selmi, collectively called Oden sols) sols have been described and have been reported to exist in an initial liquid state [11]. Additionally, sols have been observed to form from the acid decomposition of polysulfides $\left(S_{8 \text { (polysulfide) }}\right)$, the reverse reaction of the solubilization of elemental sulfur with sulfide to form polysulfide (reaction 4) $[23,26,29,35]$. The description of a liquid state for sols was based on physical macroscopic observations and the presence of a "Maltese-cross pattern" visible in crosspolarized reflected light optical microscopes at high magnification [11,17], though this may not be definitive evidence of a true liquid state [17]. The question of crystallization kinetics for initially precipitated sulfur sols is important, but beyond the scope of this paper. It is noted that sols undergo coarsening and eventually form particles of observable size that are at least eventually crystalline [11], but exactly how and when that occurs is poorly constrained. Thus $S_{8(\text { sol })}$ and $S_{8(\text { nano) }}$ may well be 
describing the same material under at least some conditions. Both hydrophobic and hydrophilic forms of sulfur sols are described to have a negative surface charge at circumneutral $\mathrm{pH}$ conditions, derived from anion sorption (hydrophobic sols) or the presence of significant longchain $\mathrm{S}$ molecules (polysulfides to polythionates) as part of the sol itself (hydrophilic sols) [11,15,34]. Kleinjan et al. [15] measured the electrophoretic mobility of biologically produced elemental sulfur as 2.3, and Janssen et al. [36], noted a difference between the measured isoelectric point and point of zero charge due to an inhomogeneous charge distribution in the polymer layer.

As with other mineral systems in which single molecules or subunits coalesce towards bulk mineral sizes and atomic configurations; elemental sulfur must as well progress via a series of reactions towards the thermodynamically most stable form, $\alpha-S_{8 \text { (bulk) }}$ :

$$
\mathrm{S}_{\mathrm{n}} \mathrm{O}_{\mathrm{m}}{ }^{2-} \rightarrow \mathrm{S}_{8 \text { (aq.) }} \rightarrow \mathrm{S}_{8 \text { (nano) }} \rightarrow \mathrm{S}_{8(\text { (sol) }} \rightarrow \alpha-\mathrm{S}_{8} \text { (bulk) }
$$

Particle coarsening, the macroscopic observation of particles increasing in size, is a combination of processes that increase overall particle size and affect the distribution of particle sizes [37]. Transition from individual molecules to clusters to nanocrystals proceeds via classical nucleation theory (CNT) that requires the formation of a 'critical nucleus', a particle at a size where its rate of growth is greater than its rate of dissolution [38]. $\mathrm{S}_{8(\mathrm{aq})}$ rings are inherently hydrophobic and their interaction quickly forms clusters of $\mathrm{S}_{8}$ rings that become $\mathrm{S}_{8 \text { (nano), and can additionally incorporate other hydro- }}$ phobic molecules that may be present to form a "dirty" sulfur cluster [23]. In the sulfur system the rate of $S_{8 \text { (aq.) }}$ aggregation to form larger clusters and nuclei would be a key part of how the mineral coarsens. For the sulfur system there is no indication of what size the critical nucleus may be, though condensed phases of elemental sulfur have been measured at sizes as low as $30 \mathrm{~nm}$ [39]. Nucleation growth would then potentially become less important under mass conservation principles when the majority of material transitions from small dissolved $\mathrm{S}_{8 \text { (aq.) }}$ and small clusters of $\mathrm{S}_{8 \text { (aq.) }}$ units to $\mathrm{S}_{8 \text { (nano) }}$ or $\mathrm{S}_{8(\mathrm{sol})}$. Coarsening would then be governed by some combination of Ostwald ripening or aggregation [40]. Ostwald ripening is a dissolution-precipitation mechanism where the growth of larger particles occurs at the expense of smaller particles due to differences in relative surface energetics [41]. Aggregation occurs via the attraction between separate clusters, critical nuclei, or larger particles to drive coarsening. Attractive forces include bonding, electrostatic interaction, dipole-charge, dipole-dipole, van der Waals interactions and hydrophobicity [38]. Given that sulfur sols and biologically produced elemental sulfur colloids are charged, aggregation must be a balance of attractive (van der Waals and hydrophobic) vs. repulsive (electrostatic) forces [15,38]. Aggregation can also occur via oriented attachment, which allows for growth towards $\alpha-S_{8}$ to proceed without the need for recrystallization on the local scale [38]. Surfactants can affect the kinetics of elemental sulfur nanoparticle growth as well, a prior study on Raffo sols derived from thiosulfate acidification [42], indicated that surfactants play a significant role in the growth kinetics of elemental sulfur nanoparticles, with the cationic surfactant CTAB (cetyltrimethyammonium bromide) having the largest effect at $28^{\circ} \mathrm{C}$. Chaudhuri and Paria also defined a critical micellar concentration, above which the coarsening rates do not continue to increase, suggesting a maximum coverage of surfactants that affects both the growth rate and the maximum particle size at $28^{\circ} \mathrm{C}$ [42].

This study looks to investigate the rates of coarsening of elemental sulfur formed as hydrophobic and hydrophilic sols, as a function of temperature, $\mathrm{pH}$, and considering the effect of ionic and nonionic lipid molecules. In this study we will utilize the following definitions for different forms of sulfur: $S^{0}$ as one molecule of atomic sulfur, $\mathrm{S}_{8}$ as a single ring of atomic sulfurs; $\mathrm{S}_{8 \text { (diss) }}$ as a single ring dissolved in a non-polar solvent; $S_{8(a q)}$ as the dissolved (in water) component of $S_{8}$ rings; $S_{8 \text { (nano) }}$ as solid nanoparticles of sulfur; $\mathrm{S}_{8 \text { (sol) }}$ as sols prepared ac-

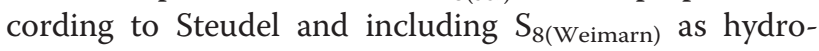
phobic Weimarn sols derived from $\mathrm{S}_{8}$ dissolved in methanol mixed with water and $S_{8 \text { (polysulfide) as sols de- }}$ rived from acidification of polysulfides under anoxic conditions, and $\alpha-S_{8}$ as mineral elemental sulfur in its most stable state at $25^{\circ} \mathrm{C}$ and 1 atm pressure. We note that some of these forms may not be distinguishable under all conditions and times, and that there can be overlap $\left(\mathrm{S}_{8 \text { (sol) }}\right.$ for instance is often also $\mathrm{S}_{8 \text { (nano) }}$ when the size is below $100 \mathrm{~nm}$ ).

\section{Results and discussion}

\section{Instrumental and experimental variability}

Dynamic Light Scattering measurements are based on the hydrodynamic properties of nanoparticles in constant (Brownian) motion measured over a time interval, and are particularly suited to measurement of spherical nanoparticles and colloids less than $5 \mathrm{~nm}$. Light scattered by these particles changes intensity in time based on this motion and that fluctuation can be fit to describe mean size, size distribution, volume distribution, and dispersity index [43-45]. Generally this does not work as well if the particles are changing size at a rate faster than the measurement window.

In order to first assess the general applicability of this method to investigate elemental particle coarsening kinetics we measured the replicability of standards and 
samples to determine both instrument error and experimental error that could be affected by a constantly changing particle population. A total of 111 replicate measurements of a $100 \mathrm{~nm}$ particle size standard control exhibited an arithmetic measurement mean of $99.35 \mathrm{~nm}$ with a standard error of the mean of $0.487 \mathrm{~nm}$. The best-fit slope is $0.01365 \pm 0.01522$ with a coefficient of determination of 0.007319 . The deviation from zero is not significant. Data include measurements with a maximum point of $119.8 \mathrm{~nm}$, a median of $98.2 \mathrm{~nm}$, and a minimum of $89.9 \mathrm{~nm}$. The dispersity index for these same standards was measured to have a measurement mean of 0.0464 with a standard error of the mean of 0.0262. Experimental variability of a solution of changing particle size was described by performing five (5) replicates (A, B, C, D, \& E) of Weimarn sol formation (Experiment set \#1). Table 1 illustrates the variability in these measurements as replicates and for the dataset combined as a whole. We find that DLS measurements can resolve particle populations changing in time, and can reasonably resolve relatively small changes in mean size with minute resolution, but that a dynamic particle population cannot be resolved with the same precision as a static population of particles. We note that the instrument cannot resolve changes in time at the very beginning of the experiments, which corresponds to a condition where particle coarsening is occurring at a rate too fast for DLS measurements. The method of cumulants $[43,46]$ to interrogate the changing scattering signal cannot resolve changes that are very fast and the software returns this case as unresolvable - we do not report any data in which the particle population changed at a rate faster than the DLS is capable of resolving.

\section{Coarsening rates}

Two distinct domains of coarsening were observed, an initial rate where the rate of particle size change was too great to quantify using DLS (the first few minutes of

Table 1 Experimental error associated with defining coarsening rates for 5 replicate experiments with the slope and 2- $\sigma$ standard error for the fit for each experiment, and the slope and 2- $\sigma$ standard error for the data from all 5 replicates used as on set of measurements to define the coarsening rate (in particle diameter as nanometers per minute)

\begin{tabular}{lll}
\hline Set & Slope $(\mathbf{n m} / \mathbf{m i n})$ & 2- $\boldsymbol{\sigma}$ standard deviation \\
\hline A & 1.66 & 0.0289 \\
B & 2.70 & 0.512 \\
C & 1.20 & 0.0860 \\
D & -0.251 & 0.248 \\
E & 0.382 & 0.319 \\
Total & 1.063 & 0.205 \\
\hline
\end{tabular}

each experiment), and an intermediate rate of relatively constant particle coarsening. A distinct bifurcation in the size v. time plots demarcates these regions, though the exact timing of this is only roughly constrained as the first interval the DLS is able to make a measurement. These domains are likely a switch from coarsening governed by classical nucleation theory and the development of a critical nucleus for each particle to coarsening governed by either Ostwald ripening or aggregation. However, given the rates the initial coarsening processes occur and the instrumental limitations described above, these measurements cannot determine the size at which this switch occurs.

\section{Coarsening as a function of temperature}

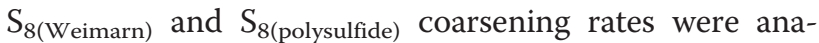
lyzed at different temperatures (Experiment set \#2) (20, 50 , and $75^{\circ} \mathrm{C}$ ) (Figure 1 ). $\mathrm{S}_{8 \text { (Weimarn) }}$ coarsening rate at room temperature $\left(20^{\circ} \mathrm{C}\right)$ is $1.65 \mathrm{~nm} / \mathrm{min}( \pm 0.304 \mathrm{~nm})$; at $50^{\circ} \mathrm{C}$ the coarsening rate is $6.62 \pm 0.506 \mathrm{~nm} / \mathrm{min}$, and at $75^{\circ} \mathrm{C}$ the coarsening rate is $19.1 \pm 0.875 \mathrm{~nm} / \mathrm{min}$. The difference between room temperature $\left(20^{\circ} \mathrm{C}\right)$ and $50^{\circ} \mathrm{C}$ is $4.97 \mathrm{~nm} / \mathrm{min}$ faster at $50^{\circ} \mathrm{C}$. The rate of coarsening at $75^{\circ} \mathrm{C}$ is 11.6 times faster than room temperature $\left(20^{\circ} \mathrm{C}\right)$.

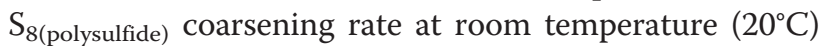
is $0.54 \mathrm{~nm} / \mathrm{min}( \pm 0.146 \mathrm{~nm})$ for $\mathrm{pH} 3.1$; at $75^{\circ} \mathrm{C}$ the coarsening rate is $5.51 \pm 0.384 \mathrm{~nm} / \mathrm{min}$ for $\mathrm{pH} 4.7$. The differences in $\mathrm{S}_{8 \text { (Weimarn) }}$ and $\mathrm{S}_{8 \text { (polysulfide) coarsening }}$ rates likely reflect fundamental differences in the surface character of each particle, with the more hydrophobic $\mathrm{S}_{8 \text { (Weimarn) }}$ particles exhibiting a substantially different temperature effect on rates at $75^{\circ} \mathrm{C}$.

Polydispersity index (PDI) was additionally measured to look at how the distribution of particle sizes change as a function of time and temperature (Figure 2). At $20^{\circ} \mathrm{C}$ the rate of change in dispersity is statistically not

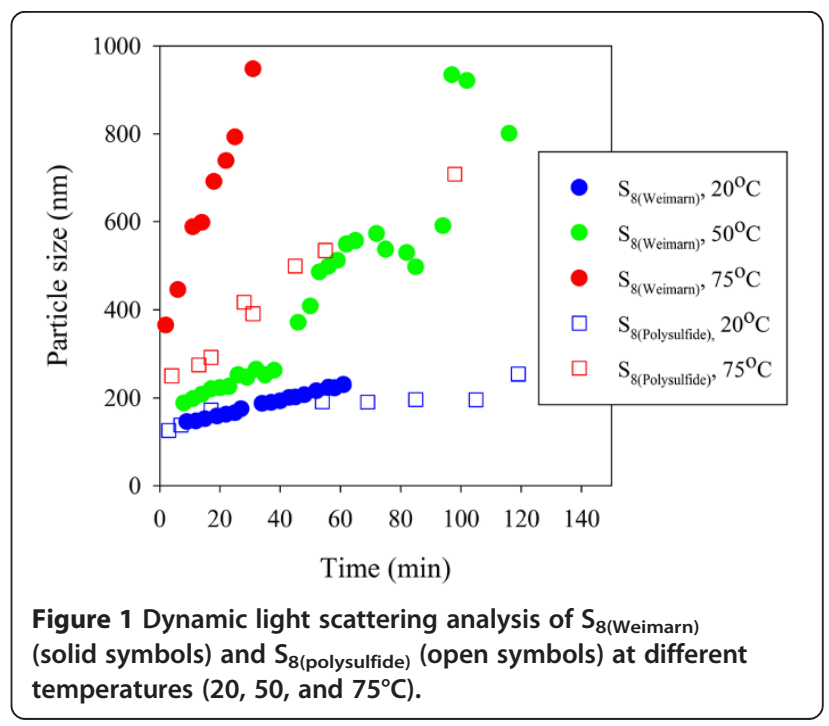




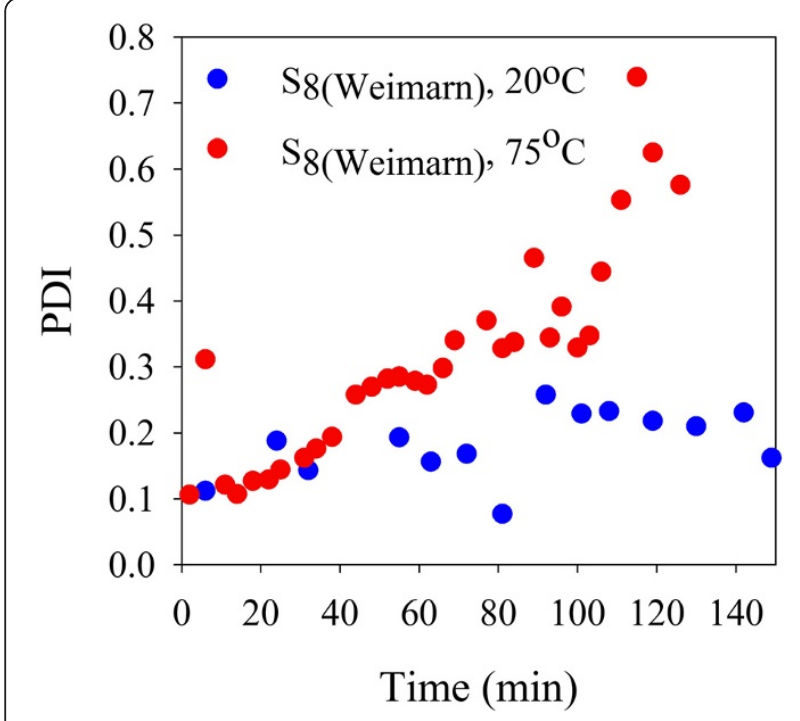

Figure 2 Polydispersity index (PDI) analysis of $\mathrm{S}_{8 \text { (Weimarn) }}$ at two different temperatures.

significantly different from zero indicating the particle size distribution stays uniform through time, consistent with Steudel's [11] observation on Weimarn sols, an effect Steudel also observed to be sensitive to the specific preparation of the sol (water added to the methanol solution). Greater dispersity indices at higher temperatures suggest a mechanism of coarsening that may relate to specific conditions of Ostwald ripening [46,47], though as a sole indicator this is insufficient to determine mechanisms.

The solubility of $\alpha-S_{8}$ increases with temperature $[24,48]$, including elemental sulfur nanoparticulates $[6,11,12]$. Weimarn $[49]$ noted "disappearing" $\mathrm{S}_{8 \text { (Weimarn) }}$ when temperature was increased. In our experiments where $\mathrm{S}_{8 \text { (Weimarn) }}$ particles are synthesized at $75^{\circ} \mathrm{C}$, the particles "disappeared" from solution by the time they reached approximately $3 \mu \mathrm{m}$ in size after approximately $100 \mathrm{~min}$. Solutions at $75^{\circ} \mathrm{C}$ become clear and the particle density in DLS instrument drops under the limit of detection. No precipitates were formed, even when the solution was cooled at room temperature $\left(20^{\circ} \mathrm{C}\right)$, suggesting the rate of coarsening measured at elevated temperatures is a minimum rate that exceeds the rate of overall particle dissolution.

\section{Coarsening as a function of $\mathrm{pH}$}

$\mathrm{S}_{8 \text { (Weimarn) }}$ rate of coarsening was described at three different pHs (3, 7 and 10), and $S_{8 \text { (polysulfide) }}$ rate of coarsening was described at three different $\mathrm{pHs}(3,7,9)$ (Experiment set \#3) (Figure 3). The rate of $\mathrm{S}_{8 \text { (Weimarn) }}$ coarsening when solution is buffered to 3 is $1.666 \pm$ $0.0288 \mathrm{~nm} / \mathrm{min}$ At pH 7, the rate is $1.658 \pm 0.0552 \mathrm{~nm} /$ min, while at $\mathrm{pH} 10$ the rate of particle coarsening is $1.207 \pm 0.05295 \mathrm{~nm} / \mathrm{min}$. $\mathrm{pH}$ measurements performed

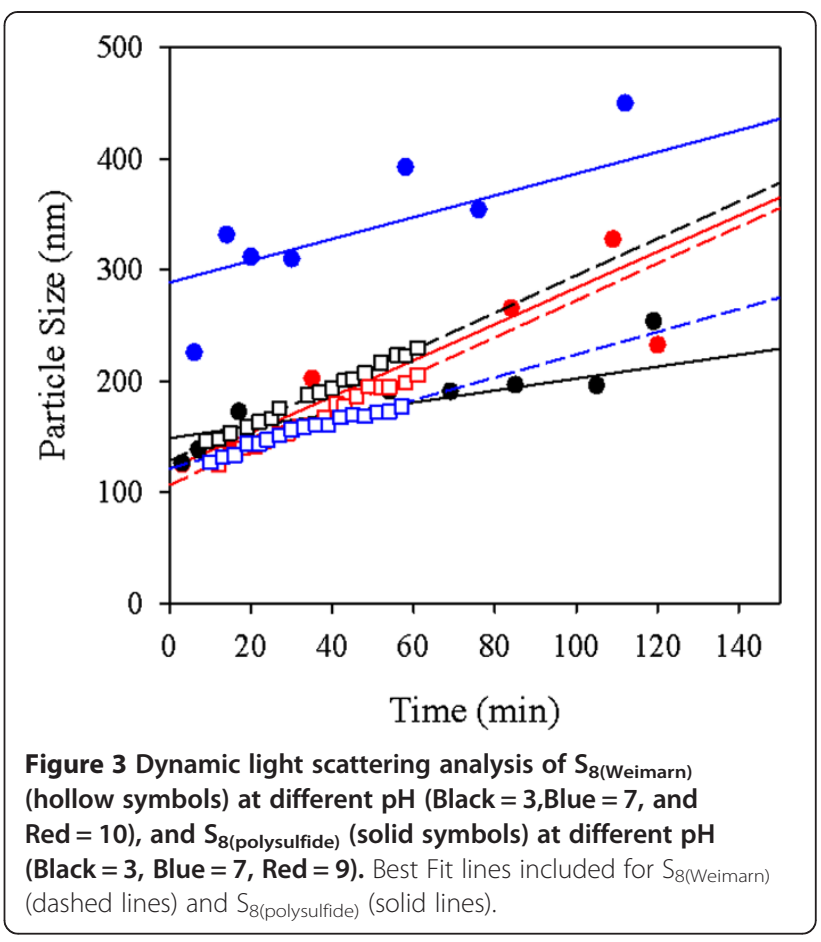

every $2 \mathrm{~h}$ confirmed there were no changes in $\mathrm{pH}$ over the course of the experiments. Statistical analysis shows that the difference between slopes is significant within the dataset but that the deviation is within that assessed previously for replicate error using DLS to describe particle systems changing in time. Since the $\mathrm{pH}$ zero point of charge $\left(\mathrm{pH}_{\mathrm{zpc}}\right)$ for elemental sulfur has been measured at 2.3 but with a heterogeneous charge due to surface polymerization $[15,36]$, these experiments were all under conditions where the particle was likely negatively charged and thus should experience electrostatic repulsion. The effect of $\mathrm{pH}$ on particle size coarsening for Weimarn sols thus suggests that $\mathrm{pH}$ does not significantly affect the rate of particle coarsening in Weimarn sols between $\mathrm{pH} 3$ and 10 . The rate at which $\mathrm{S}_{8(\text { aq.) }}$ coagulates is likely more dependent on the hydrophobicity of elemental sulfur particles, at least above the $\mathrm{pH}_{\mathrm{zpc}} \cdot \mathrm{pH}$ may have a more significant effect on the initial rates of coarsening for these particles, however, given that these rates are only constrained by 2 time points we will not attempt to quantify that effect with this dataset. $\mathrm{pH}$ does have a strong effect on rates of thiosulfate and polysulfide decomposition [20,50-53], which in turn affects the rate of supply of $S_{8(a q)}$ and subsequent coarsening.

\section{Coarsening as a function of surfactant presence}

Sodium dodecyl sulfate (SDS) was used as a model ionic surfactant to investigate the effect of surfacants on sulfur nanoparticles over a range of temperatures, a compound previously used to describe the role of surfactants in 
solubilizing $S_{8(\text { aq) }}$ from $\alpha-S_{8 \text { (bulk) }}$ [25] and the synthesis of $\mathrm{S}_{8 \text { (nano) }}$ at room temperature [39] (Experiment set \#4, Figure 4). The rate of $\mathrm{S}_{8 \text { (Weimarn) }}$ coarsening on experiments performed at $20^{\circ} \mathrm{C}$ with SDS is $0.6911 \pm 0.1268 \mathrm{~nm} /$ min while at $75^{\circ} \mathrm{C}$ the rate of coarsening is $3.533 \pm$ $0.2212 \mathrm{~nm} / \mathrm{min}$. SDS slows the coarsening process more than two-fold at $20^{\circ} \mathrm{C}$, but more than five-fold at $75^{\circ} \mathrm{C}$. $\mathrm{S}_{8 \text { (polysulfide) }}$ displays a rate of particle coarsening that also decreases when surfactant-type molecules are present; from $1.952 \pm 0.1846 \mathrm{~nm} / \mathrm{min}$ without SDS to $0.2169 \pm$ $0.01016 \mathrm{~nm} / \mathrm{min}$ with $\mathrm{SDS}$ at $20^{\circ} \mathrm{C}$, a nine-fold decrease in

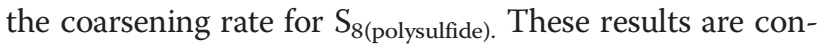
sistent with Chaudhuri and Paria [42] describing the effect of surfactants on $\mathrm{S}_{8}\left(\mathrm{Raffo}_{\mathrm{R}}\right)$, and extend the role of surfactants to higher temperature regimes for sulfur sols applicable to hydrothermal systems.

To extend the thinking for these experiments towards application to terrestrial hydrothermal systems, we compared ionic (SDS) and non-ionic (Triton-X-100) surfactants to a complex organic extract derived from pine needles (Experiment set \#5, Figure 5). Observations at several thermal springs in Yellowstone National Park (data not published) note the presence of significant amounts of pine needles as a possible external source of organic modifiers and surfactants. Because the pathways for elemental sulfur formation in these systems may be closer to one involving polysulfide, these three kinds of surfactant-type molecules (SDS, Triton-X-100, and pine needle extract) were used with $\mathrm{S}_{8 \text { (polysulfide) }}$

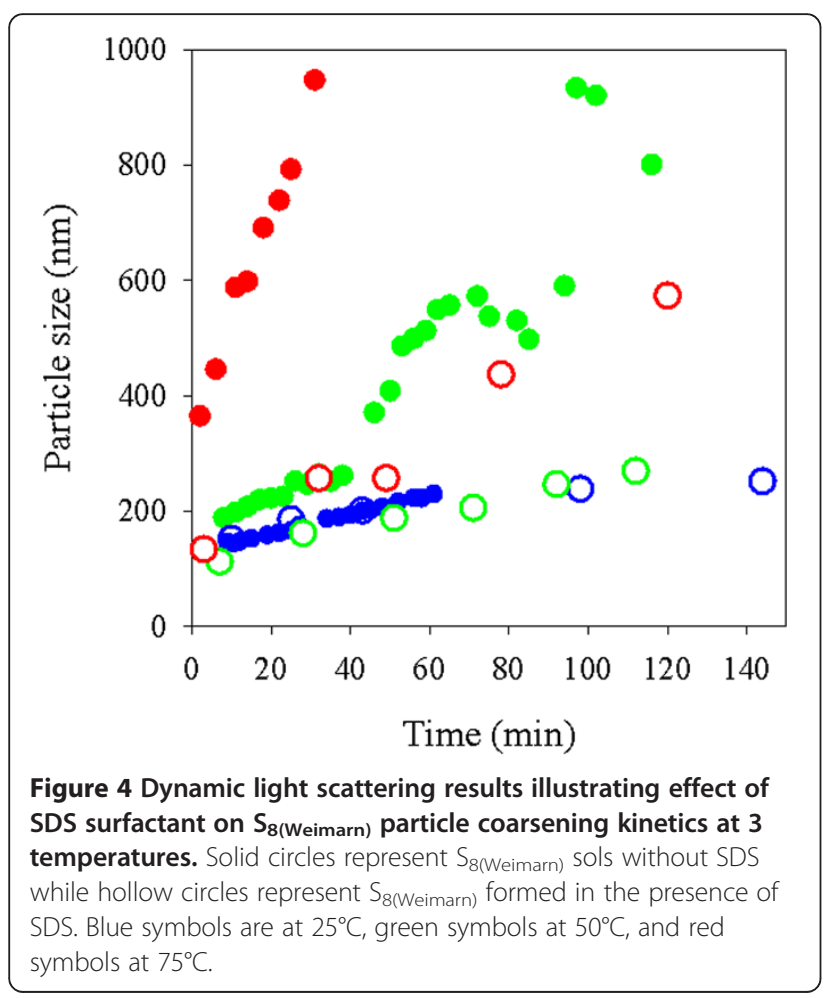

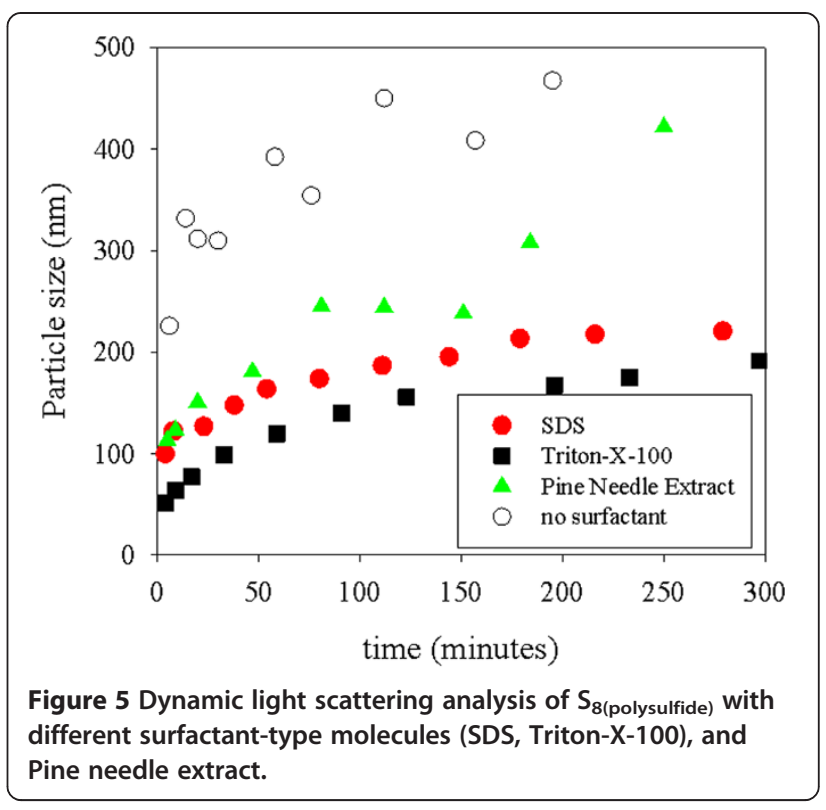

sols (Experiment set \#8; Figure 4, Table 2). Considering that the coarsening rate of $\mathrm{S}_{8 \text { (polysulfide) in the absence of }}$ surfactants at these same $\mathrm{pH}$, temperature, and solution constraints is $1.00 \mathrm{~nm} / \mathrm{min}$, pine needles can supply some component of micellar structure or other organic modifier to stabilize $S_{8(\text { nano) }}$ and $S_{8(\mathrm{sol})}$ in solution.

\section{Cryo scanning electron microscopy}

Cryogenic scanning electron microscopy images from

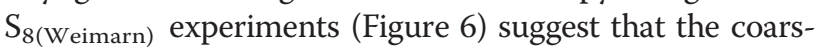
ening process occurring with this kind of sulfur sols is an Ostwald ripening process. The Ostwald ripening process is described as the exchange of volume by the mechanisms of collision and particle collapse [54]. Images from synthesized particles (Figure 6) illustrate collisions (blue circle), non-interaction (yellow circle), and the collapse (red circle) of particles.

\section{Models of particle coarsening}

Coarsening of sulfur sols likely occurs as either Ostwald ripening or aggregation after an initial stage during which the formation of critical nuclei would form. Analysis by DLS misses the initial stages of this coarsening because the rate of these initial steps are much faster than DLS techniques are able to capture at these conditions. However, we can investigate the quantifiable portion of these processes by fitting our coarsening rate data to standard models describing Ostwald ripening and aggregation based growth $[41,55,56]$, as has been done with $\mathrm{ZnS}$ and FeS nanoparticles [56,57]. We utilized an Ostwald ripening model:

$$
\mathrm{D}(\mathrm{t})=\mathrm{D}_{0}+\mathrm{k} * \mathrm{t}^{1 / \mathrm{n}}
$$


Table 2 Summary of experimental conditions for all experimental sets

\begin{tabular}{|c|c|c|c|c|}
\hline $\begin{array}{l}\text { Experiment } \\
\text { set \# }\end{array}$ & Surfactant & $\mathrm{pH}$ & $\begin{array}{l}\text { Temperature } \\
\left({ }^{\circ} \mathrm{C}\right)\end{array}$ & $\mathrm{S}_{8 \text { (sol) }}$ \\
\hline 1 & - & 2.99 & 20 & $\mathrm{~S}_{8}$ (Weimarn) \\
\hline 1 & - & 2.98 & 20 & $S_{8}$ (Weimarn) \\
\hline 1 & - & 3.10 & 20 & $\mathrm{~S}_{8}$ (Weimarn) \\
\hline 1 & - & 2.99 & 20 & $\mathrm{~S}_{8}$ (Weimarn) \\
\hline 1 & - & 2.97 & 20 & $\mathrm{~S}_{8}$ (Weimarn) \\
\hline 2 & - & 3.09 & 20 & $\mathrm{~S}_{8}$ (polysulfide) \\
\hline 2 & - & 4.7 & 75 & $S_{8}$ (polysulfide) \\
\hline $2 \& 4$ & - & 2.98 & 20 & $\mathrm{~S}_{8}$ (Weimarn) \\
\hline $2 \& 4$ & - & 2.92 & 50 & $\mathrm{~S}_{8}$ (Weimarn) \\
\hline $2 \& 4$ & - & 2.63 & 75 & $S_{8}$ (Weimarn) \\
\hline 3 & - & 2.98 & 20 & $\mathrm{~S}_{8}$ (Weimarn) \\
\hline 3 & - & 6.99 & 20 & $\mathrm{~S}_{8}$ (Weimarn) \\
\hline 3 & - & 9.98 & 20 & $S_{8}$ (Weimarn) \\
\hline 3 & - & 3.09 & 20 & $\mathrm{~S}_{8}$ (polysulfide) \\
\hline 3 & - & 8.48 & 20 & $\mathrm{~S}_{8}$ (polysulfide) \\
\hline 3 & - & 6.7 & 20 & $\mathrm{~S}_{8}$ (polysulfide) \\
\hline 4 & SDS & 3.12 & 20 & $S_{8}$ (Weimarn) \\
\hline 4 & SDS & 3.05 & 50 & $S_{8}$ (Weimarn) \\
\hline 4 & SDS & 3.07 & 75 & $\mathrm{~S}_{8}$ (Weimarn) \\
\hline 5 & SDS & 5.7 & 20 & $\mathrm{~S}_{8}$ (polysulfide) \\
\hline 5 & Triton-X-100 & 5.84 & 20 & $\mathrm{~S}_{8}$ (polysulfide) \\
\hline 5 & $\begin{array}{l}\text { Pine needle } \\
\text { extract }\end{array}$ & 5.6 & 20 & $\mathrm{~S}_{8}$ (polysulfide) \\
\hline 6 & - & 2.96 & 20 & $\mathrm{~S}_{8}$ (Weimarn) \\
\hline 6 & - & 3.09 & 20 & $\mathrm{~S}_{8}$ (polysulfide) \\
\hline
\end{tabular}

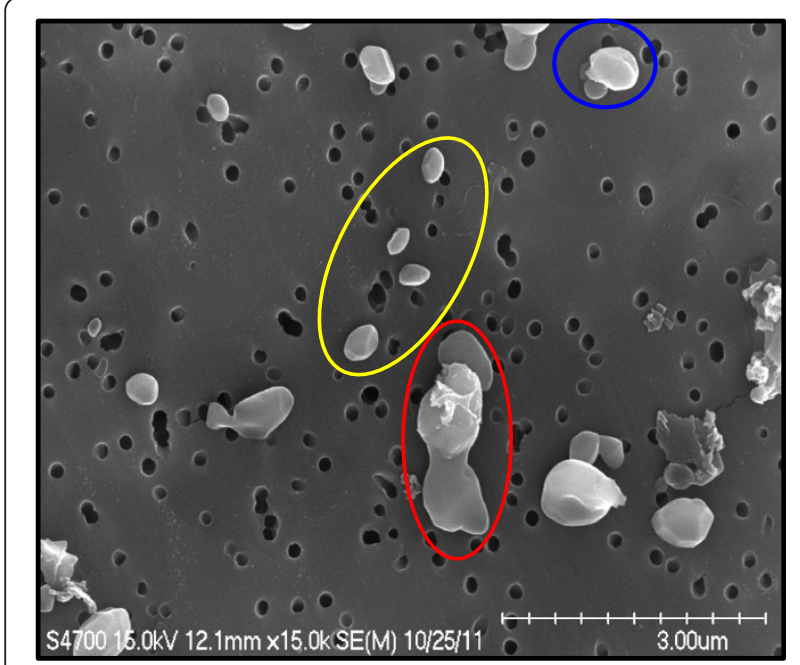

Figure 6 SEM image from $S_{\mathbf{8}}$ (Weimarn) particles. Suggested Ostwald ripening mechanisms: (Blue) Collision interaction, (Red) Collapse interaction, and (Yellow) particles that are not interacting. where the particle size at time $t, D(t)$, is a function of the initial particle size $\left(D_{0}\right.$, in this case $D_{0}$ equals zero) and a rate constant $\mathrm{k}$ with an exponent $\mathrm{n}$ that can be calculated for each experimental condition by plotting the natural $\log$ of the time and the natural $\log$ of the particle size [41,56,57]. Results of this analysis to derive $\mathrm{k}$ and $\mathrm{n}$ for experimental sets including $\mathrm{S}_{8 \text { (Weimarn) }}$ and $\mathrm{S}_{8 \text { (polysulfide) }}$ sols are listed in Table 3 . The calculated value of $\mathrm{n}$ suggests physical meaning in terms of the coarsening rate; the rate of the growth may be controlled by diffusion in solution $(\mathrm{n} \approx 1)$, diffusion at the particle surface $(\mathrm{n} \approx 2)$, or the interface dissolution/precipitation step $(\mathrm{n} \approx 3)$ [41]. Higher order exponents can indicate crystal growth controlled by diffusion on the grain/ matrix boundary $(n \approx 4)$ or crystal growth controlled by dislocation-pipe diffusion $(n \approx 5)$ [57]. Results for this Ostwald ripening exponent for Weimarn sols at different temperatures, with and without SDS as a surfactant molecule, and for polysulfides (Table 3) suggest coarsening may be controlled at the particle boundary, with higher temperature generally resulting in more diffusional control. Figure 7 shows 4 examples of sol coarsening experiments with the Ostwald ripening model data; fits for these do show deviations from the model, and the fits get worse with higher temperature but are not significantly impacted by the presence of SDS as a model surfactant. A model describing aggregation-based coarsening was also developed [41,56]:

$$
D(t)=\frac{D_{0}(\sqrt[3]{2} k t+1)}{(k t+1)}
$$

and fits for this model also calculated and plotted in Figure 7. These aggregation model fits do not fit the data as well, suggesting Ostwald ripening may be more of a controlling process for sol coarsening in these experiments. Deviation of these models from experimental data is likely due to multiple processes occurring over the time series under investigation. Notable is that the fits are worse for progressively higher temperatures; the

Table 3 Linear regression results of In time v. In particle size plots of selected experiments for fitting to standard models describing Ostwald ripening and aggregation based growth of sulfur sols

\begin{tabular}{llll}
\hline Sol type & T (and surfactant) & $\mathbf{k}$ & $\mathbf{n}$ \\
\hline Weimarn & 20 & $77 \pm 4.0$ & $3.9 \pm 0.21$ \\
Weimarn & 50 & $116 \pm 6.4$ & $4.5 \pm 0.32$ \\
Weimarn & 75 & $266 \pm 24$ & $3.0 \pm 0.26$ \\
Weimarn & 20 \& SDS & $99 \pm 2.7$ & $5.3 \pm 0.18$ \\
Weimarn & $50 \&$ SDS & $60 \pm 6.5$ & $3.3 \pm 0.26$ \\
Weimarn & $75 \&$ SDS & $73 \pm 24$ & $2.5 \pm 0.36$ \\
Polysulfide & 20 & $139 \pm 20$ & $3.6 \pm 0.34$ \\
\hline
\end{tabular}



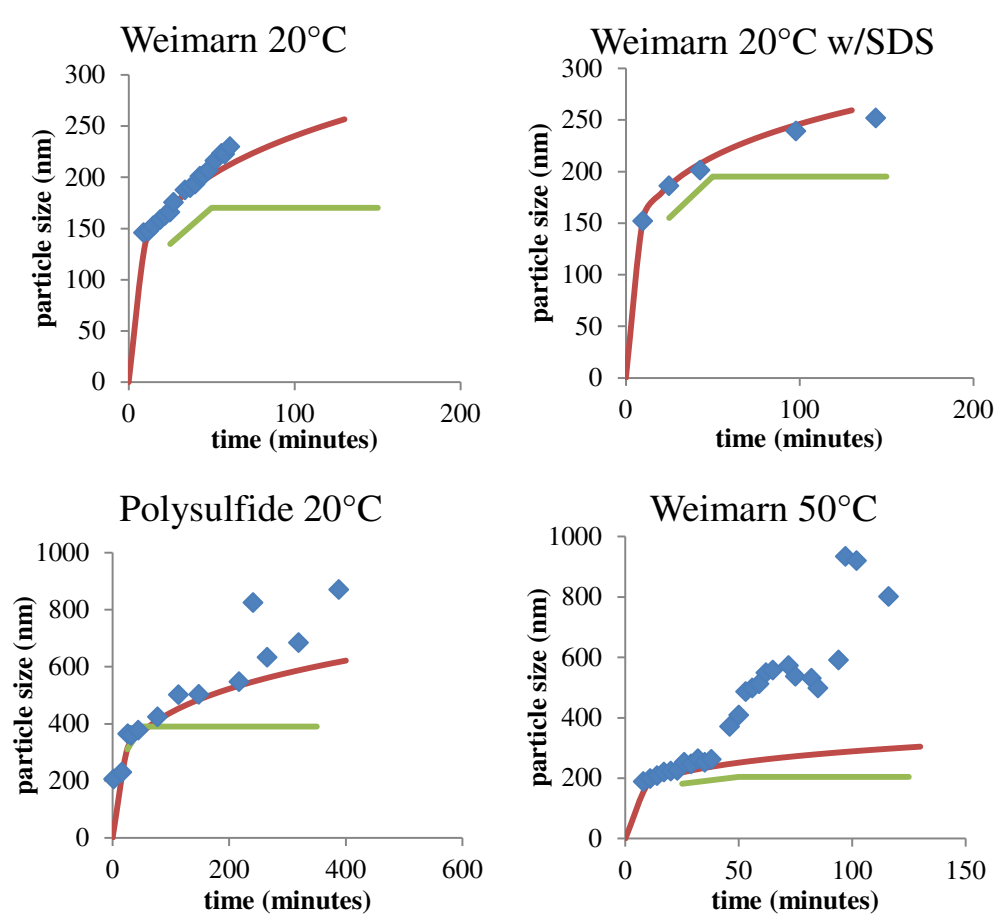

Figure 7 Example fits for selected experimental data with Ostwald ripening models utilizing rate constants $\mathrm{k}$ and exponential fits from Table 3. Blue diamonds represent data experimental data, red lines represent the fits for the Ostwald ripening model (equation 6), and green lines represent the fits for the aggregation model (equation 7), using experimentally derived parameters k and n (Table 3).

dissolution of elemental sulfur during the course of the experiments is an additional variable that these models do not account for.

\section{Experimental}

Experiments probing the coarsening kinetics of sulfur sols at different conditions are summarized in Table 2. Elemental sulfur as $\mathrm{S}_{8(\mathrm{aq})}, \mathrm{S}_{8 \text { (Weimarn) }}, \mathrm{S}_{8 \text { (polysulfide), were }}$ prepared from Precipitated Sulfur (from Fisher scientific, Lot. No. 028783) according to established techniques $[11,25]$. X-ray diffraction of the precipitated sulfur confirmed pure $\alpha-S_{8}$ as the starting material. $S_{8 \text { (diss) }}$ is produced by dissolving elemental sulfur powder $\alpha-S_{8(\text { bulk })}$ in a strong organic solvent [49]. $S_{8(\text { diss })}$ was prepared for these experiments by adding $15 \mathrm{~g}$ (excess) of precipitated sulfur in $100 \mathrm{ml}$ methanol and stirring it for several days, then decanting the supernatant and filtering through a hydrophobic 0.2 micron filter, producing a clear solution. The resulting $\mathrm{S}_{8 \text { (diss.) }}$ solution was analyzed with DLS to ensure that the solution does not have any measureable particles. Hydrophobic sols $\left(\mathrm{S}_{8(\text { Weimarn })}\right)$ was prepared by pouring $15 \mathrm{ml}$ saturated $\alpha-\mathrm{S}_{8 \text { (bulk) }}$ methanol solution into $500 \mathrm{ml}$ of $18 \mathrm{M} \Omega$ water [11,49]. $\mathrm{S}_{8 \text { (polysulfide) }}$ sample solutions were prepared daily for each experiment by acidification of a polysulfide solution with $\mathrm{HCl}$. Sodium pentasulfide salts were synthesized using methods adapted from Rosen and Tegman
[58]. Briefly, polysulfide salts were prepared by reacting $0.95 \mathrm{~g}$ anhydrous sodium sulfide with $1.55 \mathrm{~g}$ crystalline elemental sulfur that had been dried in an oven at $80^{\circ} \mathrm{C}$. All preparation and handling of the polysulfide salts were done in a dry anoxic glove box. Reagents were mixed together by grinding, placed in quartz tubes, and sealed under an atmosphere of $\mathrm{N}_{2}$ before evacuation on a vacuum line and sealing of the quartz glass using an acetylene torch. Synthesis took place through melting and reaction for $12 \mathrm{~h}$ at $210^{\circ} \mathrm{C}$, followed by an annealing step for about half an hour at $350^{\circ} \mathrm{C}$, removal and regrinding of the product under an $\mathrm{N}_{2}$ atmosphere, replacement of the mixture into another glass tube, and a final melting and reaction step at $210^{\circ} \mathrm{C}$ for $10 \mathrm{~h}$. The salts were then washed with hexane to remove residual elemental sulfur impurities, resealed under vacuum, and kept at $-20^{\circ} \mathrm{C}$ in the dark until needed.

Surfactants were used to emulate environments where organic material is present at the moment of $\mathrm{S}_{8(\text { nano) }}$ formation. Surfactants were dissolved in water before performing experiments. Sodium dodecyl sulfate (SDS, an ionic surfactant) and Triton-X-100 (a non-ionic surfactant) were used in these experiments. Additionally, pine needles were collected from an area surrounding Cinder pool, (in Yellowstone National Park) and used as a source of organic material. Pine needles were soaked in $18 \mathrm{M} \Omega$ water acidified with $\mathrm{HCl}$ to $\mathrm{pH} 4$ at $50^{\circ} \mathrm{C}$ 
overnight. After cooling the solution was filtered using $0.2 \mu \mathrm{m}$ filter paper and analyzed with DLS, no particles were detected.

For each $\mathrm{S}_{8 \text { (sol) }}$ preparation $\mathrm{pH}$ was buffered and monitored throughout the experiment (measured used a Fisher accumet $\mathrm{pH}$ meter and combination electrode). For $\mathrm{S}_{8 \text { (Weimarn) }}$ experiments, $5 \mathrm{mM}$ of buffering salts were added to avoid any significant changes in $\mathrm{pH}$. Potassium hydrogen phthalate $\left(\mathrm{C}_{8} \mathrm{H}_{5} \mathrm{KO}_{4}, \mathrm{pKa}=2.95\right)$, PIPES $\left(\mathrm{C}_{8} \mathrm{H}_{18} \mathrm{~N}_{2} \mathrm{O}_{6} \mathrm{~S}_{2}\right.$, pKa $\left.=6.76\right)$ and sodium bicarbonate $\left(\mathrm{NaHCO}_{3}, \mathrm{pKa}=10.24\right)$ were used to adjust the $\mathrm{pH}$ in the aqueous solution. After the addition of salts $3 \mathrm{M}$ $\mathrm{HCl}$ or $1 \mathrm{M} \mathrm{NaOH}$ was used to set the $\mathrm{pH}$. Potassium hydrogen phthalate was not used with SDS because $\mathrm{K}^{+}$ from the salt makes an insoluble precipitate of potassium SDS. Sulfur sols formed by the decomposition of polysulfides $\left(\mathrm{S}_{8 \text { (polysulfide) }}\right)$ were not buffered; $\mathrm{pH}$ for these experiments was adjusted to 8.48, 3.09, 6.7, and 4.7 without the addition of buffers. $\mathrm{S}_{8 \text { (polysulfide) }}$ experiments with surfactant were adjusted to $\mathrm{pH} 5.6,5.7$, and 5.84. $\mathrm{pH}$ was measured every 10 minutes using a calibrated $\mathrm{pH}$ electrode.

Temperature for all the experiments was controlled by the use of a water bath. Buffered $\mathrm{pH}$ solutions (water with salts) were thermally equilibrated for at least $30 \mathrm{~min}$ in a water bath at desired temperature before performing any experiment, including room temperature experiments. Temperature was constant throughout DLS measurements; the DLS instrument compartment is thermostated and was set at desired temperature to avoid any fluctuations in temperature that could affect the rate of coarsening of $S_{8(\mathrm{sol})}$.

\section{Conclusions}

The kinetics of $\mathrm{S}_{8 \text { (Weimarn) }}$ and $\mathrm{S}_{8 \text { (polysulfide) }}$ particle coarsening is strongly temperature dependent, and can be significantly impacted by the presence of surfactants and other organic modifiers. We extend the temperature range of defined sulfur particle coarsening to $75^{\circ} \mathrm{C}$, and show that for higher temperature conditions found in many terrestrial and marine hydrothermal systems, the coarsening rate of sulfur is very rapid. Consistent with other studies on Raffo sols $[39,42]$, this investigation of Weimarn sols and sols produced from acid decomposition of polysulfides are affected by ionic and nonionic surfactants in aqueous solutions. The presence of surfactant-type molecules in solution not only affects the solubility of $S_{8(a q)}$ in equilibrium with $\alpha-S_{8 \text { (bulk) }}$ [25], but also affects the size of sulfur nanoparticles. These parameters potentially affecting the size of elemental sulfur in hydrothermal systems may also have significant impact on other reactions involving elemental sulfur, especially the reaction between elemental sulfur and hydrogen sulfide to form polysulfides, and subsequent reactions that can affect intermediate sulfur species bioavailability [4].

Coarsening of $S_{8 \text { (nano) }}$ and $S_{8(\text { sol })}$ proceeds via a combination of classical nucleation, Ostwald ripening, and aggregation. Coarsening rate data fit to models describing both Ostwald ripening and aggregation processes $[41,56,57]$ suggest Ostwald ripening is a key process governing elemental sulfur coarsening. Deviation from these fits may be due to multiple processes (i.e. a combination of aggregation and Ostwald ripening) and/or a combination of particle aggregation with dissolution that is particularly important at higher temperature where the model fits departed more significantly. Polydispersity index measurements of the particle size distribution at higher temperature indicated a more heterogeneous size distribution that may also suggest Ostwald ripening as a key process. Additionally, particle shape and evidence for particle interaction using Cryo-SEM results suggest that the main coarsening process is also via Ostwald ripening mechanisms (collision and collapse) [54].

\section{Methods}

Dynamic light scattering (DLS) was employed to monitor particle size kinetics using a Beckman-Coulter DelsaNano $\mathrm{C}$, which utilizes photo correlation spectroscopy (PCS), where size is estimated by averaging the rate of fluctuations in laser intensity scattered by particles that are diffusing in a liquid [43]. DLS can determine mean size, size distribution, volume distribution, and molecular weight, and polydispersity index (PDI, a measurement of the distribution of particle sizes in a sample) [43,44,59]. The method of cumulants [45,59] is one of several ways that we can use the DLS data to improve particle characterization based on a statistical accumulation generation function about the mean particle size, intensity, and time. The Delsa Nano software utilizes the CONTIG algorithm to determine particle size distributions, based on an inverse Laplace transformation. Every DLS measurement for these experiments was set to capture 60 accumulations in a cuvette holder within the thermostated sampling compartment of the DelsaNano C.

Scanning electron microscopy (SEM) was used to image a sample of the Weimarn sols; because elemental sulfur is volatile, cryogenic conditions are the only reliable way to investigate the morphology of these particles. A Hitachi S4700 Field Emission Scanning Electron Microscope (FESEM) with a Gatan Alto 2500 Cryotransfer System and an Oxford INCA Energy (EDS) System was utilized at the University of Delaware Biotechnology Institute. Samples were filtered using a $0.2 \mu \mathrm{m}$ filter using a vacuum unit filter (glass). Once the sample was collected, it was put on a SEM stage and frozen using liquid nitrogen. Once the stage and sample were completely frozen, they were inserted in the SEM and analyzed. 
Linear regression models followed by one-way ANOVA tests were performed using GraphPad Prism software, version 6.00 for Mac OS X and SigmaPlot 11.0 for PC.

\section{Competing interests}

Authors declare that they have no financial or non-financial competing interests.

\section{Authors' contributions}

AG carried out the experiments, including sample preparation, all analytical work, dat analysis, and the drafting of the initial manuscript. GD conceived of the study, assisted in experimental design and data interpretation, and performed the coarsening model calculations. Both authors read and approved the final manuscript.

\section{Acknowledgements}

Dr. Clara Chan and Deborah Powell at the University of Delaware are gratefully acknowledged for providing access and assistance with cryo-SEM imaging of Weimarn sols. GKD gratefully acknowledges support of this research from NSF grant 1304352, AAG gratefully acknowledges support from NSF 13034352 and a fellowship from the University of Vermont.

\section{Author details}

${ }^{1}$ Department of Geology, University of Vermont, Delehanty Hall, Burlington 05405, VT, USA. ${ }^{2}$ School of Earth and Space Exploration, Arizona State University, Tempe 85287, AZ, USA. ${ }^{3}$ Department of Earth Sciences, Indiana University-Purdue University Indianapolis, SL118, 723W. Michigan St., Indianapolis 46202, IN, USA.

Received: 23 September 2013 Accepted: 20 July 2014 Published: 6 August 2014

\section{References}

1. Canfield DE: The Archean Sulfur Cycle and the Early History of Atmospheric Oxygen. Science 2000, 288:658-661.

2. Zerkle AL, Farquhar J, Johnston DT, Cox RP, Canfield DE: Fractionation of multiple sulfur isotopes during phototrophic oxidation of sulfide and elemental sulfur by a green sulfur bacterium. Geochim Cosmochim Acta 2009, 73:291-306.

3. Luther GW III, Church TM: Sulphur Cyling on the Continents. In Edited by Howarth RW, Stewart JWB, Ivanov MV. John Wiley \& Sons; 1992.

4. Boyd ES, Druschel GK: Involvement of intermediate sulfur species in biological reduction of elemental sulfur under acidic, hydrothermal conditions. Appl Environ Microbiol 2013, 79:2061-2068.

5. Steudel R, Eckert B: Solid Sulfur Allotropes. Top Curr Chem 2003, 230:1-79.

6. Steudel R: Liquid Sulfur. Top Curr Chem 2003, 230:81-116.

7. Amrani A, Aizenshtat Z: Reaction of polysulfide anions with $a, \beta$ unsaturated isoprenoid aldehydes in aquatic media: simulation of oceanic conditions. Org Geochem 2004, 35:909-921.

8. Rickard D: Sulfidic sediments and sedimentary rocks. Amsterdam: Elsevier; 2012.

9. Luther GW 3rd, Glazer BT, Ma S, Trouwborst RE, Shultz BR, Druschel G, Kraiya $\mathrm{C}$ : Iron and sulfur chemistry in a stratified lake: Evidence for iron-rich sulfide complexes. Aquat Geochem 2003, 9:87-110.

10. Luther GW 3rd, Findlay AJ, Macdonald DJ, Owings SM, Hanson TE, Beinart RA, Girguis PR: Thermodynamics and kinetics of sulfide oxidation by oxygen: a look at inorganically controlled reactions and biologically mediated processes in the environment. Front Microbio/ 2011, 2:62

11. Steudel R: Aqueous Sulfur Sols. Top Curr Chem 2003, 230:153-166.

12. Steudel R: Inorganic Polysulfides S n 2- and Radical Anions S n. Top Curr Chem 2003, 231:127-152

13. Meyer B: Elemental Sulfur. Chem Rev 1976, 76:367-386.

14. Steudel R: Environmental Technologies to Treat Sulfur Pollution. In Edited by Lens PN, Hulshoff W. London: IWA Publishing; 2000:1-31.

15. Kleinjan WE, Keizer A, Janssen AJH: Biologically Produced Sulfur 2003, 230:167-188.

16. George GN, Gnida M, Bazylinski DA, Prince RC, Pickering IJ: X-ray absorption spectroscopy as a probe of microbial sulfur biochemistry: the nature of bacterial sulfur globules revisited. J Bacteriol 2008, 190:6376-6383.
17. Pasteris JD, Freeman JJ, Goffredi SK, Buck KR: Raman spectroscopic and laser scanning confocal microscopic analysis of sulfur in living sulfurprecipitating marine bacteria. Chem Geol 2001, 180:3-18.

18. Klein C, Hurlbut CS: Manual of Mineralogy. New York: Wiley \& Sons; 1993.

19. Gartman A, Yücel M, Madison AS, Chu DW, Ma S, Janzen CP, Becker EL, Beinart RA, Girguis PR, Luther GW: Sulfide Oxidation across Diffuse Flow Zones of Hydrothermal Vents. Aquat Geochem 2011, 17:583-601.

20. Johnston F, McAmish L: A study of the rates of Sulfur production in acid thiosulfate solutions using S-35. J Colloid Interface Sci 1973, 42:112-119.

21. Xu Y, Schoonen MAA, Cunningham KM, Ball JW: Sulfur geochemistry of hydrothermal waters in Yellowstone National Park- I. The origin of thiosulfate in hot spring waters. Geochim Cosmochim Acta 1998, 62:3729-3743.

22. Druschel GK, Schoonen MAA, Nordstrom DK, Ball JW, Xu Y, Cohn CA: Sulfur geochemistry of hydrothermal waters in Yellowstone National Park, Wyoming. USA. III. An anion-exchange resin technique for sampling and preservation of sulfoxyanions in natural waters. Geochem Trans 2003, 4:12.

23. Steudel R: Mechanism for the Formation of Elemental Sulfur from Aqueous Sulfide in Chemical and Microbiological Desulfurization Processes. Ind Eng Chem Res 1996, 35:1417-1423.

24. Kamyshny A: Solubility of cyclooctasulfur in pure water and sea water at different temperatures. Geochim Cosmochim Acta 2009, 73:6022-6028.

25. Steudel R, Holdt G: Solubilization of elemental sulfur in water by cationic and anionic surfactants. Angew Chem Int Ed Engl 1988, 27:1358-1359.

26. Teder A: The equilibrium between elementary sulfur and aqueous polysulfide solutions. Acta Chem Scand 1971, 25:1722-1728.

27. Kamyshny A, Goifman A, Gun J, Rizkov D, Lev O: Equilibrium Distribution of Polysulfide lons in Aqueous Solutions at $25^{\circ} \mathrm{C}$ : A New Approach for the Study of Polysulfides' Equilibria. Environ Sci Tech 2004, 38:6633-6644.

28. Chen KY, Gupta SK: Formation of polysulfides in aqueous solution. Environ Lett 1973, 4:187-200.

29. Giggenbach WF: Equilibria involving polysulfide ions in aqueous sulfide solutions up to 240. Inorg Chem 1974, 13:1724-1730.

30. Kamyshny AJ, Gun J, Rizkov D, Voitsekovski T, Lev O: Equilibrium Distribution of Polysulfide lons in Aqueous Solutions at Different Temperatures by Rapid Single Phase Derivatization. Environ Sci Tech 2007, 41:2395-2400.

31. Kleinjan WE, Keizer A, Janssen AJ: Kinetics of the Reaction between Dissolved Sodium Sulfide and Biologically Produced Sulfur. Ind Eng Chem Res 2005, 44:309-317.

32. Boyd ES, Jackson RA, Encarnacion G, Zahn JA, Beard T, Leavitt WD, Pi Y, Zhang CL, Pearson A, Geesey GG: Isolation, characterization, and ecology of sulfur-respiring crenarchaea inhabiting acid-sulfate-chloride-containing geothermal springs in Yellowstone National Park. Appl Environ Microbiol 2007, 73:6669-6677.

33. Schauder R, Muller E: Polysulfide as a possible substrate for sulfurreducing bacteria. Arch Microbiol 1993, 160:377-382

34. Steudel R, Gobel T, Holdt G: The molecular composition of hydrophilic sulfur sols prepared by acid decomposition of thiosulfate. Zeitschrift für Naturforschung Teil B Anorganische Chemie, organische Chemie, Biochemie, Biophysik, Biologie 1988, 43:203-218.

35. Kleinjan WE: Wageningen Unversiteit. 2005.

36. Janssen AJ, Keizer A, Van Aelst A, Fokkink R, Yangling H, Lettinga G: Surface characteristics and aggregation of microbiologically produced sulphur particles in relation to process conditions. Colloids Surf B: Biointerfaces 1996, 6:115-129

37. Eberl DD, Drits VA, Srodon J: Deducing growth mechanisms for minerals from the shapes of crystal size distributions. Am J Sci 1998, 298:499-533.

38. Waychunas GA: Nanoparticles and the Environment. In Edited by Banfield JF, Navrotsky A. Washington, DC: Mineralogical Society of America; 2001:105-166.

39. Chaudhuri RG, Paria S: Synthesis of sulfur nanoparticles in aqueous surfactant solutions. J Colloid Interface Sci 2010, 343:439-446.

40. Shneidman VA: Early stages of Ostwald ripening. Phys Rev E 2013, 88:010401-010404

41. Gilbert B, Zhang H, Huang F, Finnegan MP, Waychunas GA, Banfield JF: Special phase transformation and crystal growth pathways observed in nanoparticles. Geochem Trans 2003, 4:20-27.

42. Chaudhuri RG, Paria S: Growth kinetics of sulfur nanoparticles in aqueous surfactant solutions. J Colloid Interface Sci 2011, 354:563-569.

43. Pecora R: Dynamic light scattering and nanoparticles in liquids. J Nanoparticle Res 2000, 2:123-131. 
44. Bloomfield VA: Static and Dynamic Light Scattering from Aggregating Particles. Biopolymers 2000, 54:168-172.

45. Koppel DE: Analysis of macromolecular polydispersity in intensity correlation spectroscopy. The method of cumulants. J Chem Phys 1972, 57:4814-4820

46. De Smet $Y$, Deriemaeker L, Parloo E, Finsy R: On the determination of Ostwald Ripening rates from dynamic light scattering measurements. Langmuir 1999, 15:2327-2332.

47. De Smet Y, Danino D, Deriemaeker L, Talmon Y, Finsy R: Ostwald ripening in the transient regime. A CryoTEM study. Langmuir 2000, 16:961-967.

48. Boulegue J, Michard G: Constantes de formation des ions polysulfures S62-, S52- et S42- en phase aqueuese. J Fr Hydrol 1978, 9:27-33.

49. Von Wiemarn PPV: Uber schwefellsungen von allen furben de spektrums. Kolloid-chem Beihefte 1926, 22:38.

50. Giggenbach WF: Kinetics of the polysulfide-thiosulfate disproportionation up to 240. Inorg Chem 1974, 13:1730-1733.

51. Kleinjan WE, De Keizer A, Janssen AJ: Kinetics of the chemical oxidation of polysulfide anions in aqueous solution. Water Res 2005, 39:4093-4100.

52. Lessner P: Kinetics of Aqueous Polysulfide Solutions. J Electrochem Soc 1986, 133:2510.

53. Kamyshny AJ, Goifman A, Rizkov D, Lev O: Kinetis of Disproportionation of inorganic polysulfides in undersaturated aqueous solutions at environmentally relevant conditions. Aquat Geochem 2003, 9:291-301.

54. Glasner K, Otto F, Rump T, Slepcev D: Ostwald Ripening Of Droplets- The Role Of Migration. Eur J Appl Math 2009, 20:1-67.

55. Joesten R: Diffusion, Atomic Ordering, and Mass Transport. In Edited by Ganguly J. New York: Springer-Verlag; 1991:345-395.

56. Huang F, Zhang H, Banfield JF: Two-stage crystal-growth kinetics observed during hydrothermal coarsening of nanocrystalline $\mathrm{ZnS}$. Nano Lett 2003, 3:373-378.

57. Guilbaud R, Butler IB, Ellam RM, Rickard D: Fe isotope exchange between $\mathrm{Fe}(\mathrm{II})_{\mathrm{aq}}$ and nanoparticulate mackinawite $\left(\mathrm{FeS}_{\mathrm{m}}\right)$ during nanoparticle growth. Earth Planet Sci Lett 2010, 300:174-183.

58. Rosen $E_{1}$ Tegman $\mathrm{R}: \mathrm{A}$ preparative and $\mathrm{X}$-ray powder diffraction study of the polysulfides $\mathrm{Na}_{2} \mathrm{~S}_{2}, \mathrm{Na}_{2} \mathrm{~S}_{4}$, and $\mathrm{Na}_{2} \mathrm{~S}_{5}$. Acta Chimica Scandanavia 1971 25:3329-3336.

59. Frisken BJ: Revisiting the method of cumulants fot the analysis of dynamic light scattering data. Appl Opt 2001, 40:4087-4091.

doi:10.1186/s12932-014-0011-z

Cite this article as: Garcia and Druschel: Elemental sulfur coarsening

kinetics. Geochemical Transactions 2014 15:11.

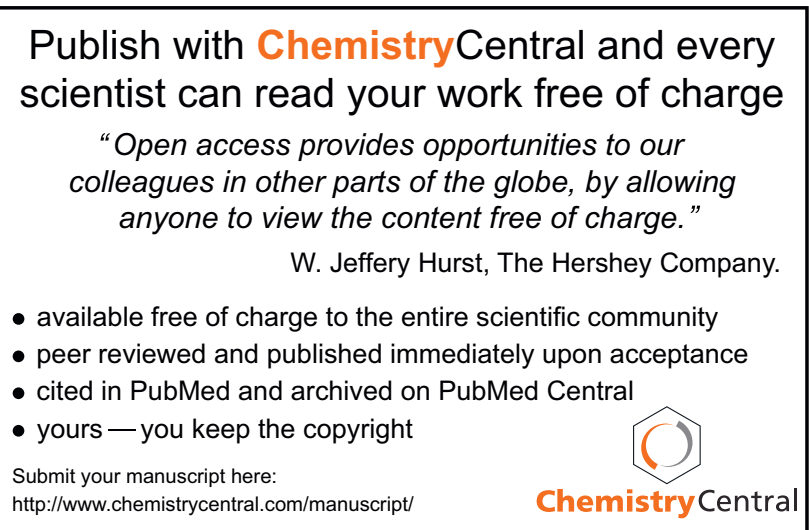

